
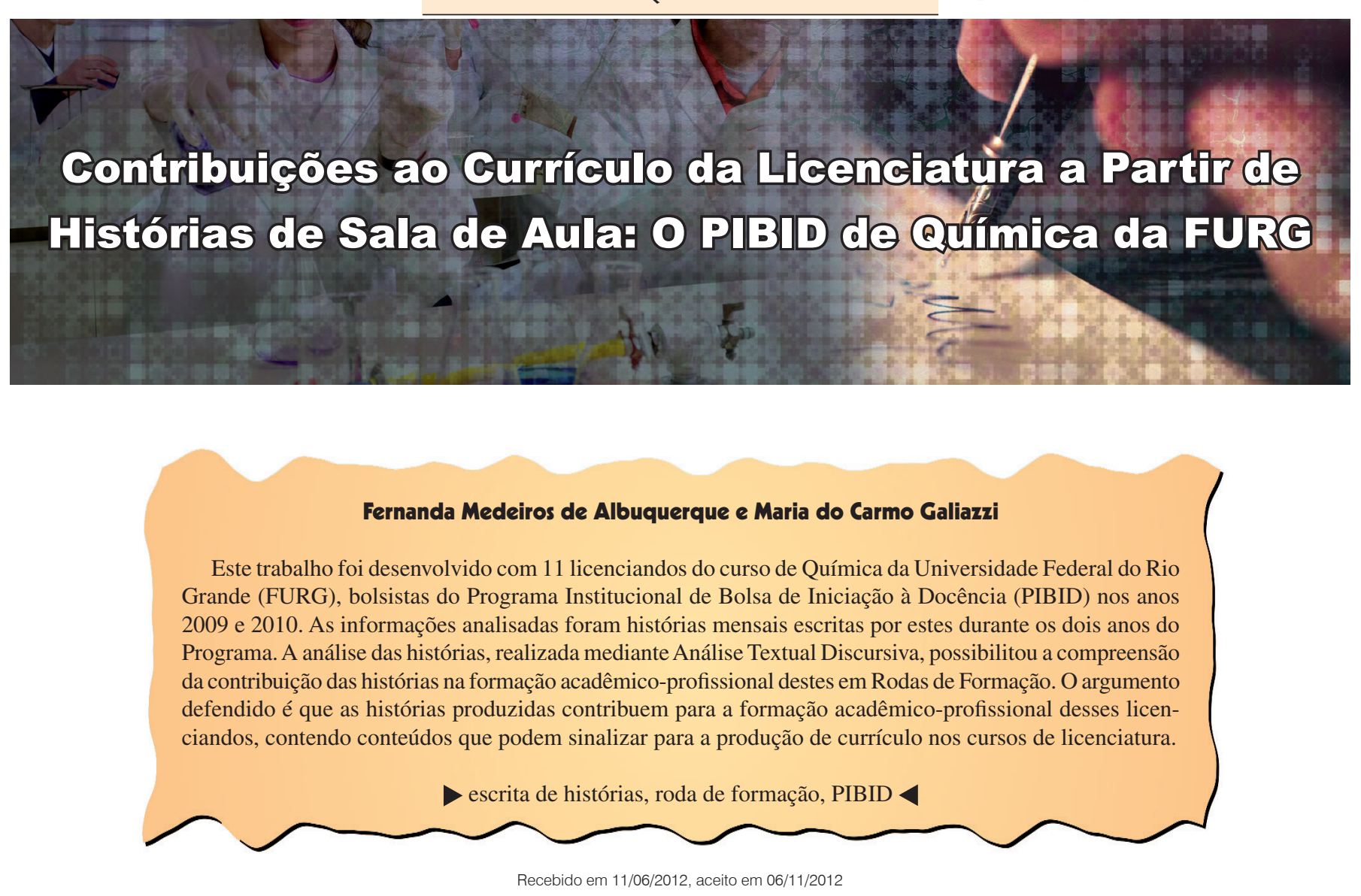

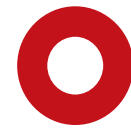
argumento a ser fortalecido neste trabalho é de que as histórias produzidas nas Rodas de Formação do Programa Institucional de Bolsa de Iniciação à Docência (PIBID) contêm conteúdos produtores de currículo para os cursos de Licenciatura em Química. Para a construção desse argumento, foram analisadas as histórias de sala de aula escritas por formandos da Universidade Federal do Rio Grande (FURG), participantes da Roda de Formação do PIBID.

Iniciando por uma discussão sobre a importância da escrita de histórias de sala de aula, o texto apresenta as Rodas de Formação como possibilidades de partilha, diálogo e reflexão sobre a prática docente. A partir disso, apresenta-se o PIBID de Química da FURG, como oportunidade em espaços coletivos de aprendizagem, seguido pelos resultados alcançados, com a análise das histórias escritas pelos formandos.

O PIBID de Química da FURG, assim como os estágios previstos no currículo dessa licenciatura, oportunizam o contato dos licenciandos com a escola desde cedo, tendo

A seção "Ensino de Química em Foco" inclui investigações sobre problemas no ensino de Química, com explicitação dos fundamentos teóricos, procedimentos metodológicos e discussão dos resultados. eles a possibilidade de vivenciar situações reais. Por meio dessa vivência, os licenciandos poderão perceber as limitações que possuem os professores para resolver problemas do dia a dia escolar.

No contexto analisado, os estágios e o PIBID podem ter muitas semelhanças e contribuições no processo de formação do educando. No entanto, o aluno do curso de Licenciatura em Química, que também é bolsista do PIBID, além de ter o contato com a escola desde cedo, pode ter um espaço de formação, contando com a presença e participação do seu professor tutor e demais professores da rede pública. Ele tem a oportunidade de partilhar ideias com o professor da escola em encontros semanais nas Rodas do PIBID de química da FURG. Dessa forma, o contato é mais próximo do que o encontro feito apenas na escola.

A aproximação entre o licenciando e o professor da escola possibilita em ambos a reflexão sobre suas escolhas, sobre a inserção no coletivo docente e sobre a sua constituição como profissional da educação. O contato é feito em uma Roda de Formação com múltiplos olhares e vozes. Nela, o licenciando tem a oportunidade de partilhar experiências, contribuindo para a sua formação e para a formação de colegas e professores. 


\section{Escrita de histórias de sala de aula}

Nas escolas, a escrita de histórias narradas por professores pode surgir como fundamental incentivo aos docentes para que assumam a autoria e a reflexão sobre o ambiente escolar, recriando seus saberes, problematizando suas experiências e possibilitando a transformação da sua prática. A narrativa, portanto, poderá ser mais uma possibilidade que o professor tem para refletir sobre a docência, oportunizando que ele tome decisões de acordo com os questionamentos que foram provocados pela sua escrita.

Por meio da escrita e divulgação de experiências, o professor tem a oportunidade de conversar sobre suas preocupações e expectativas com outros interlocutores. Ao narrar, eles compartilham e conversam com outros colegas, numa linguagem prática, com suas próprias palavras, pois por meio da escrita e da leitura de histórias, os professores podem discutir problemas, dúvidas e aflições comuns (Souza, 2010). O processo possibilita o confronto de diferentes pontos de vista, retomada e esclarecimentos de questões, posicionamento individual e coletivo (Almeida, 2007).

$\mathrm{O}$ autor pode narrar histórias que ocorreram ou que foram inventadas por ele numa possibilidade de expressão de sentimentos e ideias que não experimentaria se não as escrevesse ou dissesse a alguém (Marques, 2008). A leitura e a escrita de histórias aparecem como momentos em que as aprendizagens acontecem. Momentos esses em que o imaginário permite a soltura de amarras com o racional, oportunizando ao autor dizer algo a si mesmo, e ao leitor interpretar a escrita de acordo com crenças, experiências, saberes e realidade.

Quando o professor conta uma história de sala de aula, ele conta uma sequência de eventos não para explicar o que está sendo contado, mas para sujeitar a história a diferentes interpretações, sendo possível, por meio dela, eliminar a dúvida do ouvinte e principalmente eliminar a dúvida dele mesmo. Durante a escrita, a experiência narrada sofre um processo de racionalização e distanciamento e permite ao autor analisar e refletir sobre as suas experiências e decisões.

Por meio da escrita, o professor consegue distanciar-se das suas certezas e incertezas e visualizar o que estava até então oculto na sua percepção como formador. Portanto, ao contar histórias de sala de aula, o professor contribuirá para o seu processo de formação (Souza, 2010). Os docentes que assumem o papel de autores compartilham suas leituras de mundo, trajetórias e saberes pedagógicos com colegas e conhecedores da linguagem pedagógica.

No processo de escrita, os professores transformam-se em narradores de suas próprias experiências pedagógicas (Suárez, 2008). Com isso, eles reconstroem parte da sua trajetória profissional, atribuindo sentidos ao que realizaram em determinados momentos. A narrativa de experiências dos professores, portanto, além de oportunizar a reflexão de suas ações, transforma-se numa oportunidade de documentação da prática profissional.

Histórias narradas por professores são materiais que possibilitam conhecer o que esses profissionais fazem, pensam e sentem quando desenvolvem suas atividades na escola (Suárez, 2003). Para o autor, a documentação narrativa das próprias experiências escolares dos professores contém relatos pedagógicos que nos possibilitam interpretar o mundo escolar do ponto de vista dos seus protagonistas.

Ela se torna o registro da memória pedagógica da escola, por meio do qual se tem a possibilidade de acompanhar o que foi e está sendo feito na instituição. Por meio da leitura desse material, pode-se conhecer os diferentes pontos de vista, o modo particular como o docente organiza seu trabalho e as decisões tomadas em certos momentos. A escolha da experiência que será narrada permite conhecer também o que os docentes enfatizam e o que é omitido por eles.

A leitura e a divulgação desses registros possibilitam a interação entre os docentes e também o incentivo de novos olhares e ações sobre a mesma ação. A circulação desse material promove a discussão e permite que atividades realizadas por um sejam reconstruídas por outros em outros contextos.

É importante que, além dos professores da escola, os licenciandos durante o seu processo de formação também sejam incentivados a refletirem sobre as suas práticas por meio da escrita. $\mathrm{O}$ confronto com a própria prática e a reflexão coletiva e pessoal permitem que o sujeito em formação acadêmico-profissional perceba, a partir da sua linguagem, suas limitações e busque estratégias para qualificar-se. As contradições, os conflitos, as resistências e os limites do processo de formação do licenciando, ao serem narrados, podem contribuir para a sua compreensão e provocar mudanças (Souza, 2010).

Via narrativa, explicitamos contradições, conflitos e limites que percebemos na nossa formação (Suárez, 2003), portanto, a documentação dessas experiências permitirá o registro da trajetória de formação dos licenciandos e o conhecimento de fragilidades e potencialidades dessa caminhada.

Quando o licenciando escolhe qual história contará, ele revela a importância que dá para determinado tema. Bruner (2001) acredita que uma história tem dois lados: uma sequência de eventos e uma avaliação implícita dos eventos contados. A história, portanto, traz consigo a avaliação que o sujeito tem sobre o fato. Só pelo sujeito ter escolhido contar uma história e não outra, ele já demonstra a relevância que dá para determinado fato. 
O conjunto dos registros escritos pelos licenciandos permite documentar os caminhos percorridos, possibilitando perceber quais os temas que lhes causam angústias e como as situações narradas são enfrentadas. Nesse caso, a documentação narrativa é a memória da formação acadêmico-profissional, e a leitura desse material permite uma melhor compreensão da formação dos licenciandos, podendo contribuir para a melhoria do curso de licenciatura.

Entretanto, como o licenciando pode sair do isolamento e partilhar seus questionamentos, experiências e saberes construídos?

\section{Rodas de formação}

Ao longo da nossa trajetória de vida, fazemos parte de muitas rodas: da merenda, das brincadeiras, de samba, de amigos, do chimarrão, de professores, de estudo. Muitas são as trocas feitas nessas diferentes rodas. Muito se aprende, se conhece e se socializa. A inserção ou não do sujeito em determinadas rodas depende das suas características e relações estabelecidas ao longo da sua história. Essa configuração em roda pode instigar a comunicação. Os sujeitos conseguem olhar-se e, com isso, as interações são percebidas com mais facilidade. Ocorrem trocas de olhares, de argumentos, de críticas, de experiências. Quando se está em roda, as trocas acabam sendo inevitáveis. Conseguimos, por meio dela, conhecer um pouco do outro, observando comportamentos, reações e manifestações.

Quando nos referimos à Roda de Formação, entretanto, não utilizamos mais a palavra troca, mas sim partilha. Qual a diferença? Para Warschauer (2001), partilha não tem a perspectiva quantificável da troca. Na partilha, é necessário perceber como o outro escuta o que foi dito. Ao ensinar aos outros o que sabe, o sujeito consegue, além de contribuir para a formação dos demais participantes, aprender mais a partir de um exercício de escuta e reflexão sobre a sua própria fala. É entendido, portanto, que as Rodas trazem a ideia de retorno à pessoa, na qual o que importa são os significados e os aprendizados que elas fazem.

As Rodas de Formação se destacam pela qualidade das partilhas entre os participantes (Warschauer, 2001). Nesta, todos têm algo a ouvir e a dizer. Essa configuração com o objetivo de formar-se formando (Lima, 2011) mostra a possibilidade de espaços em que as aprendizagens se constroem por meio da relação entre os sujeitos. Entende-se que, por meio do diálogo, da escuta de diferentes pontos de vista, complementado pela discussão teórica, cada um pode refletir, confirmar ou reformular argumentos. Ao discutir experiências, os sujeitos poderão ter outra visão do ocorrido, transformando a si mesmo e ao outro pela escuta da experiência, podendo levar a uma nova compreensão dos fatos.
Para Warschauer (2001), conversar, além de desenvolver a capacidade de argumentação lógica, pressupõe a presença do outro, implicando nas emoções, no respeito de saber ouvir e falar, em enfrentar as diferenças e no esforço de se colocar no ponto de vista do outro. Ao conversar, portanto, temos a oportunidade de criar o espírito coletivo, pois as criações de uma comunicação não pertencem a um indivíduo, mas ao grupo.

Defende-se que as Rodas de Formação sejam espaços que retirem os professores do isolamento e impulsionem o desenvolvimento de sujeitos pesquisadores da sua prática, que consigam contribuir para a sua formação e para a formação dos seus pares (Albuquerque e Galiazzi, 2011). Nessas Rodas, são dadas oportunidades para a partilha de experiências e, com estas, o surgimento de questionamentos que incentivem a busca de novos argumentos que possam ser divulgados na própria Roda.

Quando se forma um grupo de formação em Rodas, seja esse constituído por alunos, professores em formação e/ou professores em exercício, a presença de diferentes pontos de vista impulsiona as aprendizagens. Apesar de experiências anteriores, há sempre uma faixa de potencialidades para novos conceitos, crenças e práticas, sendo possíveis pelo trabalho mediado (Maldaner, 2003). O trabalho precisa ser mediado para que conceitos expressos em falas iniciais adquiram novos significados.

O trabalho coletivo e mediado permite uma intervenção desejada por sujeitos que querem mudar a sua ação. Essa intervenção permite às pessoas internalizar de maneira mais intensa os novos conceitos e, com isso, passar para novos níveis de entendimento da sua prática. As discussões de experiências, juntamente com o estudo de textos teóricos, oportunizam reflexões, possibilitando a partilha das experiências entre sujeitos em diferentes estágios de aprendizagem, e que problemas não resolvidos individualmente possam ser resolvidos com o auxilio da discussão coletiva.

A exposição de ideias e a oportunidade de partilha de histórias, experiências vividas, saberes e dificuldades encontradas possibilitam que os participantes percebam que os problemas que enfrentam também são enfrentados por outros. Seja o participante um professor ou este um aluno, ele receberá o incentivo para enfrentar seus medos e ousar, pois terá a força do conhecimento construído a partir da partilha e da reflexão coletiva.

Warschauer (1993) alerta para o cuidado para que as conversas na Roda não se tornem meras conversas informais. Destaca que "para que as Rodas realmente alimentem a construção dos conhecimentos, é necessário o registro, pois o registro é um grande instrumento para a sistematização e organização dos conhecimentos" (p. 56). 
O registro faz com que as conversas nas Rodas sejam formalizadas e que os diálogos sejam ampliados. Dessa forma, ocorre um comprometimento maior com o que é falado e se oportuniza o diálogo com outras Rodas de Formação. Quando registramos, temos a possibilidade de ampliar a reflexão sobre a nossa caminhada. Podemos acompanhar o andamento da Roda, os conflitos gerados, os problemas vividos e as estratégias encontradas para tentar resolvê-los. Os registros podem ser maneiras de eternizar alguns momentos vividos na Roda ou vividos a partir dela.

\section{PIBID de química da FURG}

Uma das Rodas de Formação em que o licenciando de química da FURG pode participar é do PIBID, aprovado na FURG em 2008 e em andamento desde janeiro de 2009, que tem encontros semanais presenciais e é constituídas por licenciandos, professores da educação básica e da universidade e alunos do Programa de Pós-Graduação em Educação em Ciências da FURG.

O PIBID é executado no âmbito da Coordenação de Aperfeiçoamento de Pessoal de Nível Superior (CAPES) e tem por finalidade fomentar a iniciação à docência. Além disso, este contribui para a melhoria da educação básica, pois proporciona a formação permanente de professores experientes atuantes no ensino básico e de professores da universidade. O Programa faz uma articulação entre as licenciaturas, a escola e os sistemas estaduais e municipais, visando à melhoria do ensino nas escolas públicas.

Entre as propostas do PIBID, está o incentivo à carreira do magistério nas áreas da educação básica com maior carência de professores com formação específica: Ciências e Matemática de $5^{\mathrm{a}}$ a $8^{\mathrm{a}}$ série do ensino fundamental e física, química, biologia e matemática para o ensino médio. Além disso, o Programa também visa contribuir para a valorização do magistério, elevar a qualidade da formação inicial de professores nos cursos de licenciatura e incentivar as escolas públicas de educação básica por meio da mobilização de seus professores como coformadores dos futuros docentes.

No ano de 2009, o PIBID-FURG envolvia quatro licenciaturas, as quais compuseram os subprojetos de química, física, biologia e matemática, devido à falta de professores na região para atuar nessas disciplinas. Essa política pública de formação de professores ampliou-se na FURG no ano de 2010, envolvendo todas as licenciaturas e consolidando a relevância do projeto em um trabalho entre as unidades educacionais na universidade. Em cada subprojeto, são desenvolvidas ações específicas da licenciatura correspondente, destacando-se o fato de que todos eles propõem atividades semanais na escola, proporcionando aos licenciandos a oportunidade de maior participação em ações docentes.
O projeto institucional, com suas ações previstas para dois anos, contempla licenciandos bolsistas, podendo envolver outros licenciandos voluntários, professores supervisores da rede pública e, no mínimo, cerca de 2.000 alunos da educação básica, pois a mesma escola pode ser contemplada por diferentes áreas do conhecimento.

O PIBID é caracterizado por propiciar espaços de mediação reflexiva entre universidade, escola e sociedade. Esses espaços refletem objetivos, interesses e preocupações do curso, possibilitando a existência de uma rede de partilha de saberes e construção de conhecimento. É por meio dessas relações que as Rodas do PIBID de Química da FURG se tornam espaços privilegiados de questionamento e investigação da prática profissional.

Esse projeto é uma oportunidade de formação de professores em Roda de Formação. Nesta, o licenciando pode partilhar experiências, medos e angústias em estar na sala de aula, além de construir materiais para as aulas e aprofundar seu estudo teórico, contando com a presença do professor da escola. São oportunidades de diálogo, construção de conhecimento e valorização da formação do professor.

Entende-se que, muitas vezes, os alunos aprendem na imitação, observação, mas também elaborando seu próprio modo de ser a partir da análise crítica dos modelos de professor que tiveram (Pimenta, 2010). A inserção dos licenciandos em sala de aula e a discussão dessa experiência são momentos em que o licenciando poderá observar criticamente, refletir e propor alternativas para situações reais.

Na Roda do PIBID, a escrita oportuniza momentos fundamentais no processo de formação do professor, sendo incentivada por meio de atividades como: escrita de um portfólio coletivo (escrita do professor do ensino básico com os licenciandos que atuam na escola), escrita de histórias de sala de aula, produção de materiais para a sala de aula, entre outras atividades sugeridas ao longo do Programa.

A escrita de histórias tem como objetivo a escrita, a leitura e a problematização da sala de aula. O portfólio coletivo foi pensado com o objetivo de registrar experiências, angústias e sugestões, a partir de um tema escolhido pelo grupo formado pelo professor tutor e os licenciados que o acompanham. No portfólio, também são discutidas as atividades feitas em sala de aula, bem como registradas as impressões do grupo envolvido na proposta.

\section{Conteúdos produtores de currículos nos cursos de licenciatura}

A partir da análise das histórias escritas pelos 11 participantes do PIBID, buscou-se compreender como esses licenciandos, com o objetivo de buscar conteúdos produtores de currículo nos cursos de licenciatura, percebem a escola, 
potencializando a formação acadêmico-profissional de licenciandos de química. A pesquisa foi orientada por uma análise qualitativa, utilizando-se a metodologia de Análise Textual Discursiva (Moraes e Galiazzi, 2007) e buscando nas histórias escritas pelos formandos subsídios para estabelecer reflexões e conclusões sobre a proposta.

Após leitura e releitura de cada uma das histórias, foi feito um exercício de escolha de três palavras-chave que levaram à escolha de um título. Além desse exercício, para cada história, foi escrito um resumo com o intuito de facilitar no momento da organização dos dados e compreender a intencionalidade da escrita. Portanto, foi respeitada a forma escolhida pelo autor para contar cada história, entendendo cada uma como uma unidade narrativa.

O contar história segue algumas regras universais que guiam o processo de escrita da história. Uma vez que o narrador tenha começado, a história sustentará o fluxo da narração. Portanto, o contador de história narra aqueles aspectos de acontecimentos que são relevantes para ele, sendo mencionado na narrativa em sua totalidade, com começo, meio e fim. Sendo assim, uma análise qualitativa de uma narrativa só terá sentido quando respeitadas as afirmações feitas no contexto escolhido pelo autor.

Foram analisadas 220 histórias escritas nos dois anos do PIBID (2009 e 2010). Destas, 115 mostraram conteúdos a serem trabalhados no curso de licenciatura. Dentre os conteúdos, estão: a desarticulação entre a universidade e a escola - em que os licenciandos demonstram ter dificuldades em compreender as diferentes possibilidades de cada um destes locais; a sala de aula - em que são reveladas dificuldades relacionadas às atitudes dos alunos; a avaliação - compreendida pelos licenciandos como um instrumento de poder do professor; e o caso da educação - sendo compreendido pelos licenciandos como a urgência em valorizar a profissão do professor.

\section{Desarticulação entre a universidade e a escola}

As histórias sobre esse tema contam a dificuldade dos licenciandos em se adaptarem a situações diferentes das que eles encontram na universidade. São destacados problemas nas escolas como a falta de professores, as trocas de horários e as prioridades da gestão de uma instituição de ensino. Eles demonstram que têm dificuldades em compreender a rotina da escola, bem como os recursos, a estrutura e os funcionários disponíveis para realizar determinadas tarefas.

A dificuldade em compreender a organização da escola é demonstrada por Nínive (abril de 2009) em uma de suas histórias:

No dia 28 de abril, foi comemorado o dia da educação. Mas, temos algo para comemorar? Na minha longa caminhada, já tive oportunidade de me deparar com situações que, às vezes, me fazem parar e pensar até que ponto eu quero ser professor. Estamos em um tempo em que nós, professores, somos para o aluno simplesmente um despejador de informações. O aluno vai para aula e espera o conteúdo, mas a maneira como foi apresentado não importa. $O$ que importa é se o professor vai liberar mais cedo ou não. Reuniões pedagógicas no horário de aula? Sim, vamos fazer! Lembro-me de vezes em que toda a escola soltava cedo porque tinha reunião e chegávamos na sala dos professores e estava acontecendo um chá de bebê. Não sou assim tão cética a ponto de acreditar que professor deve ir para escola dar a sua aula e ir para casa. Deve ser um prazer dar aula e não uma obrigação, pois o aluno sente quando temos ou não prazer em dar aula. Mas, que prazer resiste às escolas destruídas? Falta segurança. Cada vez mais, há casos de professores mortos por motivos banais. Uma simples nota baixa já é motivo para assassinato. Como trabalhar bem sem saber até que ponto podemos cobrar do nosso aluno? Somos cobrados pela quantidade de alunos que são aprovados, mas a qualidade deles não é levada em conta. O que importa são números. Números que diminuem cada vez mais quando se trata de salário. Chega a ser ridículo o salário de um professor. Para conseguir se sustentar acaba por trabalhar 60 horas e não tem tempo de preparar uma aula boa. Entra no círculo vicioso: está muito cansado, não prepara a aula, o aluno nota o desinteresse do professor e acaba se desinteressando, o professor vê o aluno sem vontade e acaba não produzindo também. Realmente deve haver motivos para se comemorar o dia da educação. Eu só não consegui achar algum ainda.

Nínive demonstra a sua insatisfação com a organização na escola. Conta que são muitos os motivos para o aluno não ter aula e que, além de o professor parecer não valorizar a importância do seu trabalho, o governo também o faz por meio de baixos salários. Ela se sente insegura em relação à profissão, acreditando que a escola seja um local que desrespeite o horário das aulas e que pouco permite ao professor desenvolver um trabalho com seriedade e serenidade.

Durante a formação na universidade, são raros os momentos em que os licenciandos deveriam ter aula e, por um motivo ou outro, acabam não tendo. Eles se acostumam com a organização e com os recursos disponíveis atualmente na universidade e, quando chegam às escolas públicas, esperam encontrar um espaço também organizado. Quando não 
encontram o que esperam, o sentimento de decepção vem à tona. O que fazer com esse sentimento?

Uma alternativa pode ser a de promover ou intensificar a discussão da profissão professor nos cursos de formação. Dessa forma, o licenciando poderá perceber o quanto o professor pode contribuir para visão que os alunos têm das aulas. Poderá compreender a importância em dar o exemplo em vez de ser mais um desmotivador.

Podemos compreender a profissão do professor como um semeador da felicidade na escola, não para que seja alienado às questões relacionadas aos baixos salários e ao número elevado de horas trabalhadas, mas para que perceba a importância do seu papel na formação dos alunos. Para Rios (2003), a felicidade em dar aula está presente quando os alunos aprendem os conteúdos e quando eles respeitam os direitos de todos e não só nos momentos de recreio e comemorações. Faz-se necessário que os licenciandos compreendam a importância do seu papel e reconheçam e discutam em Rodas de Formação as situações que poderão enfrentar na escola para que possam contribuir em resgatar a felicidade do professor em dar aulas.

Ao estar atento às informações obtidas no contato com a escola, o licenciando tem a possibilidade de perceber a escola como um espaço para problematização e construção do conhecimento. A escola pode ser compreendida de acordo com suas limitações e as atividades podem ser replanejadas, buscando ir além dos obstáculos encontrados, porém atendendo às necessidades da escola. É importante, portanto, perceber que os saberes não estão na universidade e, destas, serão levados à escola (Zeichner, 2010). Os saberes serão construídos no envolvimento dos licenciandos com a sua formação e na articulação entre os conhecimentos acadêmicos e a prática profissional.

A sala de aula: o medo em relação às atitudes dos alunos

As histórias sobre o medo em relação às atitudes dos alunos contam problemas de indisciplina e de indiferença ao estudo, mostrando que os formandos, apesar de estarem em contato com a escola desde o início do curso, não esperavam, no encontro com o outro, encontrar determinadas atitudes em sala de aula.

Dificuldade com atitudes relacionadas com a falta de pontualidade nas aulas é percebida na história da Amanda (junho de 2010):

No primeiro dia em que comecei minha Unidade na turma, ao chegar na sala de aula, uma surpresa: a sala de aula não tinha mais porta.

No momento, fiquei muito preocupada com esta situação, pois conhecendo a escola e a turma, sabendo que os alunos não são muito quietos, fiquei mais preocupada com o barulho do corredor e o entra $e$ sai dos alunos.

No momento em que entrei na sala de aula, me deparei com poucos alunos dentro da sala, e muitas mochilas em cima das classes. Perguntei pelos colegas e alguns me disseram que a maioria estava nos corredores. Alguns permaneceram na entrada da porta e eu tive de ir lá e pedir para entrarem. Como não tem porta, eles acabam ficando na entrada da sala, conversando com outros alunos de outras turmas. Esses que estavam lá entraram, então dei início à aula. Passado alguns minutos, chegaram os outros que estavam provavelmente no pátio no andar de baixo. Quando entraram, como não ouviram o início, precisei explicar de novo para esses que não estavam o que havia falado antes. Confesso que já havia percebido durante as observações da turma que isto acontecia, porém agora que sou a professora, percebo o quanto isto atrapalha o andamento da aula. E agora sem porta, mais difícil vai ser, pois na escola, não tem monitor para controlar a entrada e saída dos alunos da sala de aula, quer dizer, tem uma pessoa que fica no andar de baixo, controlando a porta da escola, mas os alunos têm acesso livre da sala de aula para o pátio. Isto me deixou um pouco apreensiva no primeiro dia.

Amanda demonstra que já acompanhava esses alunos nas suas atividades de estágio e que, por esse motivo, sente-se receosa em assumir a turma e enfrentar o comportamento dos alunos que julga inadequado como, por exemplo, a falta de pontualidade destacada na história. A licencianda acredita no diálogo entre o professor e os alunos e convida os que ainda não estão na sala de aula a fazerem parte da Unidade de Aprendizagem que pretende desenvolver. Mesmo não sendo atendida inicialmente, a licencianda mostra-se preocupada com a aprendizagem dos alunos, dispondo-se a explicar a atividade o quanto for necessário.

$\mathrm{Na}$ história, pode ser percebido também que a Amanda sente-se insegura em lidar com adolescentes que têm interesses diferentes do que ela gostaria. A partir do exercício da docência, ela está tendo a oportunidade de perceber as dificuldades em trabalhar com os alunos, reafirmando a importância da prática na formação acadêmico-profissional.

Não só a Amanda manifesta insatisfação com as atitudes dos alunos, mas muitos licenciandos ou até mesmo professores em exercício questionam que os alunos não são os mesmos de antigamente (Rios, 2003). Argumento defendido pela autora é que também não se pode mais ser professor como antigamente. É necessária uma reflexão crítica do 
trabalho docente para que se encontre instrumentos metodológicos que permitam trabalhar melhor e que colaborem na formação dos alunos.

Ainda assim, é importante destacar que mesmo com propostas que pressupõem a participação ativa dos alunos, como a Unidade de Aprendizagem proposta por Amanda, há contradições e resistências. Nas atividades que contam com a participação ativa dos alunos, é importante ter-se consciência de que resistências podem ocorrer, para ter tranquilidade com essa situação (Machado e Mortimer, 2007).

A tranquilidade proposta pelos autores poderá ser adquirida com a experiência profissional adquirida no dia a dia da sala de aula. Uma proposta para os cursos de formação de professores pode ser o investimento em relatos de experiências de professores da rede pública aos licenciandos, criando um ambiente de partilha que possibilite a busca em conjunto de possíveis alternativas para se estabelecer um melhor diálogo com os adolescentes. Por meio do diálogo entre o professor e os alunos, já utilizado inicialmente por Amanda, eles têm a oportunidade de se conhecer e estabelecer uma relação de confiança e parceria para o trabalho.

Entende-se que o aluno é efetivamente diferente, principalmente no que diz respeito à sua maturidade em relação a atitudes. O professor precisa respeitá-lo, o que, recorrendo novamente à Rios (2003), não significa deixar como está, mas intervir, permitindo o desenvolvimento das potencialidades. Essa intervenção poderá ocorrer a partir do diálogo e respeito mútuo, sendo esses recursos essenciais para uma boa relação entre o professor e os alunos.

A identidade dos adolescentes se estabelece por meio de uma rede de significados, diante da qual os jovens estão dizendo quem são, o que aceitam ou não (Marques, 2009). Toda a identidade exige um opositor e uma relação para que possa ser construída. Por meio de manifestações agressivas, os adolescentes podem estar querendo mostrar, segundo o autor, a sua insatisfação em relação às contradições do sistema sociocultural e econômico desigual. Conquistar esse aluno, perceber e mostrar-lhe a importância da escola para que possam atuar e se inserir na sociedade de forma crítica e transformadora são desafios para o professor.

\section{A avaliação: o poder em exercício}

Assim como as atitudes dos alunos, muitas foram as histórias sobre o tema avaliação, apontando mais um conteúdo a ser trabalhado na licenciatura. Nestas, aparecem inseguranças dos licenciandos em relação à postura dos alunos com os instrumentos de avaliação, tais como cópia de trabalhos, o despreparo dos alunos no momento das provas e a injustiça de professores quando avaliam um aluno. Os licenciandos demonstram que têm dificuldade em compreender os critérios de avaliação e em perceber como a avaliação pode ser justa, sendo esta compreendida como um instrumento de poder do professor.

Na história da Julie (dezembro de 2009), é possível perceber que os alunos não estão sendo escutados, e que a avaliação está sendo utilizada como um instrumento para o professor decidir quem será aprovado ou não. A licencianda apresenta dificuldade em compreender a avaliação como uma oportunidade de perceber na manifestação dos alunos o que eles estão aprendendo.

Neste ano de 2009, pude acompanhar algumas turmas na escola que faço estágio e, independente das turmas magistério ou ensino médio, em qualquer uma delas, os alunos agem da mesma maneira com relação à avaliação, ou seja, em trabalho ou prova, alguns vão e fazem, já outros não aparecem e fazem após a segunda chamada, mas quando chegam para fazer a segunda chamada, ainda tem alguns alunos que apenas assinam o nome, olham a prova e nem a menos tentam fazer alguma questão, e isso acontece não só durante o ano, como também na última avaliação. Então, chega o final do ano letivo, e estão todos ou pelo menos a grande maioria em busca da aprovação, uns merecedores, já outros infelizmente nem tanto.

Essa observação, infelizmente, é uma das muitas coisas ruins que acontece na escola e na sala de aula, mas apesar das coisas ruins com as quais nos deparamos durante o ano, cada vez que entro na sala de aula tento dar o melhor de mim para eles e, com isso, pude perceber principalmente nas aulas que administrei que a turma gostou. Até o final da aula, ficava tensa e nervosa e, quando terminava, tinha uma sensação de missão cumprida e, quando eu ia embora, a turma agradecia pela aula que lhes havia dado ou apenas por alguma ajuda para tirar dúvidas e isso me deixou muito feliz e satisfeita.

Nesta história de dezembro, resolvi fazer uma síntese do que mais me chamou a atenção na sala de aula durante este ano.

Julie escreve sobre como os alunos da escola que acompanha agem em relação às avaliações. A sua insegurança em relação ao descaso dos alunos é muito grande, pois conta que muitos faltam nos dias de avaliação e outros entregam a atividade em branco. A licencianda revela, por meio da sua história de insegurança com a avaliação, que está se constituindo como uma professora que se preocupa com a aprendizagem dos alunos e que valoriza a relação entre professor e aluno.

A avaliação consiste na realização de ações, pelo professor e pelos alunos, com o objetivo de acompanhar a evolução de aprendizagens, sendo fundamental ao professor estar atento à necessidade de replanejamento das ações de ensino (Ramos e Moraes, 2010). É importante, portanto, repensar se os alunos estão sendo ouvidos e o que eles estão manifestando ao não realizar as provas com seriedade.

Segundo os autores, a avaliação nas escolas está centrada no desempenho quantitativo dos alunos, geralmente por meio de aplicações de provas com perguntas dissertativas que geram pontos que serão agregados à nota do aluno. Nesse 
sentido, é importante discutir, nos cursos de formação, o conceito de prova e repensar a avaliação da aprendizagem, considerando esta como compreensão do que o aluno consegue produzir.

É importante discutir: qual o objetivo de uma atividade se esta não contribuir para compreender quais as dificuldades dos alunos? Ao perceber o que o aluno está aprendendo, o professor pode repensar suas estratégias para possibilitar o avanço da aprendizagem. Não basta, portanto, criar atividades. O professor precisa adequar o tempo que tem para corrigi-las e analisá-las, buscando a valorização do que o aluno consegue produzir dentro dos seus limites e possibilidades.

De acordo com os argumentos defendidos por Ramos e Moraes (2010), a avaliação é um processo que não tem como objetivo separar os alunos em aprovados ou reprovados. A avaliação consiste em comparar o aluno com ele mesmo, buscando a compreensão e os avanços das dificuldades de cada um. Para isso, é necessário envolver os alunos em atividades que possam demonstrar o que sabem, buscando compreender como cada um aprende.

Ao expressar o que aprenderam por meio da escrita ou do diálogo, os professores podem conhecer as lacunas e os questionamentos dos alunos e planejar situações que incentivem a superação dessas lacunas e a busca de respostas aos seus questionamentos. A manifestação de diferentes pontos de vista e o envolvimento na construção de argumentos podem contribuir para que o aluno sinta que é escutado e que faz parte do seu processo de aprendizagem. A aproximação entre professor e aluno contribui para o fortalecimento da autoestima do aluno e possibilita que ele possa ser avaliado de forma a ampliar o que já conhece.

\section{Caso da educação: desvalorização da profissão}

As histórias sobre a desvalorização da profissão mostram a insegurança dos licenciandos ao perceberem que a profissão é desvalorizada pelos próprios professores. Os licenciandos acreditam que sejam os docentes os agentes de mudança na educação e argumentam - sem muito questionar se existem nem quais são os motivos prováveis - que estes estão pouco interessados.

Susie (março de 2009) narra com desânimo o olhar que as pessoas têm sobre a profissão professor:

Neste mês, estávamos conversando em uma aula de didática sobre a desvalorização do professor, o que me remeteu a uma história que vivenciei no $3^{\circ}$ ano do ensino médio. Como é de praxe, no $3^{\circ}$ ano, alguns professores acabam perguntando a seus alunos sobre para qual curso escolherão prestar vestibular. Como a licenciatura já era decisão tomada para mim, logo me posicionei. No momento em que falei que iria tentar fazer um curso de licenciatura, meu professor me respondeu: licenciatura não, não sejas professora! Até mesmo alguém que serve cafezinhos pode ganhar mais e se ocupar menos. Fiquei extremamente decep- cionada com aquele que para mim seria meu futuro colega de profissão. Portanto, o que podemos observar é que se os próprios integrantes da classe se discriminam e se humilham, o que esperar da sociedade em geral? Um advogado, por exemplo, ficaria feliz em ver um futuro colega de profissão, porém o professor desmotivou e desvalorizou quem poderia perpetuar o seu trabalho. No entanto, mesmo ficando sem ação naquele momento, hoje estou no $3^{\circ}$ ano do curso de Química Licenciatura, e com plena convicção de que minha vontade de dar aula é a grande razão de que consegui chegar até aqui. E com certeza, estimularei, quando estiver exercendo minha profissão, os futuros colegas que tomarem esta decisão.

Susie conta que teve oportunidade em uma aula na universidade em discutir a desvalorização do professor. A licencianda se mostra insatisfeita ao lembrar que os próprios professores não incentivam a profissão. Sente-se insegura com a falta de orgulho do docente e acredita que a sociedade valoriza pouco o professor por consequência de ele se valorizar pouco. Apesar de ter sido desestimulada, após o contato com a escola e com as dificuldades encontradas na instituição, a licencianda continua acreditando na importância da sua profissão.

É necessário discutir o investimento de verbas públicas destinadas à educação, para que seja possível ampliar o discurso para além de lamentar que as pessoas valorizam pouco a profissão. Lamentar que a profissão não é socialmente reconhecida é demonstrar que sabemos pouco sobre a nossa história (Arroyo, 2011). O argumento do autor é que se faz necessário compreender o valor social dado à formação. $\mathrm{O}$ médico é socialmente reconhecido, porém o professor parece que ainda não. Por quê? É necessário fazer com que os outros acreditem na profissão professor e, para isso, é preciso conhecer como o professor chegou a essa desvalorização da profissão.

Desde as décadas de 1980 e 1990, já existiam sinais de crise do magistério no Brasil devido aos baixos salários e às más condições de trabalho (Diniz-Pereira, 2011). O autor argumenta que se questiona a formação do profissional da educação, porém as discussões sobre as condições que se têm no mercado de trabalho ainda não são significativas. Acredita que é necessário compreender que nem tudo de ruim que ocorre na escola é culpa do professor. Compreender e reivindicar condições adequadas de trabalho, salários dignos, tempo para planejamento são fundamentais para a realização do trabalho docente.

As pesquisas sobre a docência acabam fundamentando-se, na maioria das vezes, na didática, na tecnologia do ensino, no conhecimento e na aprendizagem, e acabam não considerando o tempo de trabalho do professor, o número de alunos, os recursos disponíveis, o controle da administração e a burocracia (Tardif, 2009). É preciso, portanto, ampliar o conhecimento sobre a profissão para compreender os motivos que levam ao descontentamento dos professores. 


\section{Considerações finais}

Neste texto, defendeu-se a escrita de histórias de sala de aula como oportunidade de reflexão sobre a docência e como possibilidade de documentação dos caminhos trilhados durante a formação acadêmico-profissional. Argumentou-se sobre as Rodas de Formação como oportunidades de aprendizagens coletivas, além de destacar o PIBID de Química da FURG como um desses espaços em que o diálogo, a partilha de experiências e a escrita possibilitam que problemas não resolvidos individualmente possam ser resolvidos com o auxilio da discussão coletiva, contando com a presença de licenciandos e professores.

As dificuldades encontradas pelos licenciandos no

\section{Referências}

ALBUQUERQUE, F.M. e GALIAZZI, Maria do Carmo. A formação de professores em Rodas de Formação. Revista Brasileira de Estudos Pedagógicos. v. 92, n. 231, p. 386-398, 2011.

ALMEIDA, B. A escrita na formação continuada de professoras alfabetizadoras: práticas de autoria. 2007, 252f. Tese (doutorado) - Programa de Pós-Graduação em Educação, Universidade de São Paulo, São Paulo, 2007.

ARROYO, M.G. Ofício de mestre: imagens e autoimagens.

Petrópolis: Vozes, 2011.

BRUNER, J.S. A cultura da educação. Porto Alegre: Artmed, 2001.

DINIZ-PEREIRA, J.E. O ovo ou a galinha: a crise da profissão docente e a aparente falta de perspectiva para a educação brasileira. Revista Brasileira de Estudos Pedagógicos. v. 92, n. 230, p. 34-51, 2011.

LIMA, C.A. O diário em Roda, Roda em movimento: formar-se ao formar professores no PROEJA. 2011. 187f. Tese (Doutorado em Educação Ambiental) - Programa de Pós-Graduação em Educação Ambiental, Universidade Federal do Rio Grande, Rio Grande, 2011.

MACHADO, A.H. e MORTIMER, E.F. Química para o ensino médio: fundamentos, pressupostos e o fazer cotidiano. In: ZANON, L.B. e MALDANER, O.A. (Orgs.). Fundamentos e propostas de ensino de química para a educação básica no Brasil. Ijuí: Unijuí, 2007.

MALDANER, O.A. A formação inicial e continuada de professores de química: professor/pesquisador. Ijuí: Unijuí, 2003.

MARQUES, M.O.S. Juventude, escola e sociabilidade. In: PIMENTA, S.G. (Org.). Saberes pedagógicos e atividade docente. São Paulo: Cortez, 2009.

MARQUES, M.O. Escrever é preciso: o princípio da pesquisa. Petrópolis: Vozes, 2008.

MORAES, R. e GALIAZZI, M.C. Análise Textual Discursiva. contato com a escola podem ser compreendidas não como falhas da escola, mas como possibilidades de conteúdos que deverão ser trabalhados nos cursos de licenciatura. Por meio das histórias, portanto, os licenciandos sinalizam suas limitações, possibilitando que tais conteúdos sejam trabalhados em Rodas de Formação.

Fernanda Medeiros de Albuquerque (fernanda.albuquerque@osorio.ifrs.edu.br), doutora em Educação em Ciências pela FURG, é professora de Química no Instituto Federal de Educação, Ciência e Tecnologia - Campus Osório. Osório, RS - BR. Maria do Carmo Galiazzi (mcgaliazzi@gmail.com), doutora em Educação pela Pontifícia Universidade Católica do Rio Grande do Sul, experiência em formação de professores, é professora associada da FURG e coordenadora institucional do PIBID da FURG. Rio Grande, RS - BR.

Ijuí: Unijuí, 2007.

PIMENTA, S.G. e LIMA, M.S.L. Estágio e docência. São Paulo: Cortez, 2010.

RAMOS, M. e MORAES, R. A avaliação em química: contribuição aos processos de mediação da aprendizagem e de melhoria do ensino. In: SANTOS, W.L.P. e MALDANER, O.A. (Orgs.). Ensino de química em foco. Ijuí: Unijuí, 2010.

RIOS, T.A. Compreender e ensinar: por uma docência da melhor qualidade. São Paulo: Cortez, 2003.

SOUZA, M.L. Histórias de constituição e ambientalização de professores de química em rodas de formação em rede: colcha de retalhos tecida em partilhas (d)e narrativas. 2010. 182f. Tese (Doutorado em Educação Ambiental) - Programa de Pós-Graduação em Educação Ambiental, Universidade Federal do Rio Grande, Rio Grande, 2010.

SUÁREZ, D.H. Narrativa docente, practicas escolares y reconstrucción de la memoria pedagógica. In: Manual de capacitación sobre registro y sistematización de experiencias pedagógica. Modulo 1. Ministerio de Educación, Ciencia y Tecnología. Buenos Aires, 2003.

A documentação narrativa de experiências pedagógicas como estratégia de pesquisa-ação-formação de docentes. In: PASSEGI, M.C. e BARBOSA, T.M.N. Narrativas de formação e saberes biográficos. Natal: EDUFRN; São Paulo: Paulus, 2008.

TARDIF, M. e LESSARD, C. $O$ trabalho docente: elementos para uma teoria da docência como profissão de interações humanas. Petrópolis: Vozes, 2009.

WARSCHAUER, C. A roda e o registro: uma parceria entre professor, alunos e conhecimento. Rio de Janeiro: Paz e Terra, 1993. Rodas em rede: oportunidades formativas na escola e fora dela. Rio de Janeiro: Paz e Terra, 2001.

ZEICHNER, K. Repensando as conexões entre a formação na universidade e as experiências de campo na formação de professores em faculdades e universidades. Educação, v. 35, n. 3, p. 479-504, 2010.

Abstract: Classroom's stories contribution to the chemistry licensing courses: the chemistry PIBID from FURG. This study presents a research concerning the academic and professional training of Chemistry grad students at Universidade Federal do Rio Grande (FURG) who joined PIBID (a program that encourages teaching licensing courses) in 2009 and 2010. The research was developed with eleven students at their final year in PIBID program and the data analyzed were stories monthly written by these participants during their two years in the program. The analyses of the stories written by the participants of this research was taken by Textual Discursive Analysis, allowing a greater comprehension of the academic and professional training in the Wheels of Education of Chemistry graduates at FURG. The thesis raised is that stories produced in Wheels of Education have contents that can point out issues for the syllabus of licensing courses which potentiate the academic and professional training of Chemistry graduates.

Keywords: Classroom stories; Wheels of Education; PIBID 